\title{
Cerebral perfusion in relation to cognitive function and type 2 diabetes
}

\author{
A. M. Tiehuis - K. L. Vincken • E. van den Berg • \\ J. Hendrikse - S. M. Manschot - W. P. T. M. Mali • \\ L. J. Kappelle • G. J. Biessels
}

Received: 10 March 2008 / Accepted: 4 April 2008/ Published online: 17 May 2008

(C) The Author(s) 2008

\begin{abstract}
Aim/hypothesis Underlying mechanisms for decreased cognitive functioning in patients with type 2 diabetes are unclear. In the general population, cerebral hypoperfusion is a risk factor for cognitive dysfunction and dementia. Reduced cerebral perfusion may account for cognitive impairments in diabetic patients relative to controls.

Methods A total of 98 patients with type 2 diabetes and 47 control participants underwent neuropsychological evaluation. Total cerebral blood flow (CBF) was assessed non-invasively by measuring the volume flow in the internal carotid arteries and basilar artery with two-dimensional phase-contrast magnetic resonance angiography. Relative total $\mathrm{CBF}$, a measure of mean total cerebral perfusion, was obtained by expressing total CBF per $100 \mathrm{ml}$ brain parenchyma volume. Results Patients with type 2 diabetes performed worse on neuropsychological tests $(p<0.05)$. Total CBF per $100 \mathrm{ml}$ brain parenchyma volume did not differ between participants with and without diabetes (difference $-2.3 \mathrm{ml} \mathrm{min}^{-1}$ $\left.100 \mathrm{ml}^{-1} ; 95 \% \mathrm{CI}-6.0,1.3\right)$. In the entire group, total CBF
\end{abstract}

A. M. Tiehuis $\cdot$ K. L. Vincken - J. Hendrikse $\cdot$ W. P. T. M. Mali Department of Radiology and Image Sciences Institute, University Medical Center Utrecht,

Utrecht, the Netherlands

E. van den Berg $\cdot$ S. M. Manschot $\cdot$ L. J. Kappelle $\cdot$ G. J. Biessels Rudolf Magnus Institute of Neuroscience,

Department of Neurology, University Medical Center Utrecht, Utrecht, the Netherlands

\section{A. M. Tiehuis $(\bowtie)$}

Department of Radiology (Hp E01.332),

University Medical Center Utrecht,

P.O. Box 85500, 3508 GA Utrecht, the Netherlands

e-mail: a.m.tiehuis@umcutrecht.nl per $100 \mathrm{ml}$ brain parenchyma volume was positively associated with cognitive functioning (0.09 SD increase in composite $z$ score per $10 \mathrm{ml} \mathrm{min}^{-1} 100 \mathrm{ml}^{-1}$ increase in relative total $\mathrm{CBF}$ ). This association was not affected by type 2 diabetes.

Conclusions/interpretation Although total CBF per $100 \mathrm{ml}$ brain parenchyma volume was associated with cognitive functioning, it did not explain cognitive impairments in patients with type 2 diabetes relative to controls.

Keywords Cerebral perfusion · Cognition · Magnetic resonance imaging · Type 2 diabetes

$\begin{array}{ll}\text { Abbreviations } \\ \text { BA } & \text { basilar artery } \\ \text { CBF } & \text { cerebral blood flow } \\ \text { 2D-PC } & \text { two-dimensional phase-contrast } \\ \text { FLAIR } & \text { fluid-attenuated inversion recovery } \\ \text { ICAs } & \text { internal carotid arteries } \\ \text { IR } & \text { inversion recovery } \\ \text { MRA } & \text { magnetic resonance angiography } \\ \text { MRI } & \text { magnetic resonance imaging } \\ \text { PET } & \text { positron emission tomography } \\ \text { SPECT } & \text { single photon emission computed tomography }\end{array}$

\section{Introduction}

Type 2 diabetes increases the risk of cognitive impairment and vascular dementia [1]. In the general population, cerebral hypoperfusion is a risk factor for cognitive dysfunction and dementia [2-4]. Therefore, differences in cerebral perfusion between patients with and without diabetes might explain their differences in cognitive function. 
Previous studies on cerebral perfusion in patients with type 2 diabetes are scarce. Reductions up to $30 \%$ in several brain regions $[5,6]$ and a lower overall cerebral perfusion [6] have been observed in single photon emission computed tomography (SPECT) or positron emission tomography (PET) studies. A recent study using non-invasive arterial spin labelling magnetic resonance imaging (MRI) did not find an effect of type 2 diabetes on regional cerebral perfusion [7]. Small sample sizes and potential selection bias may explain part of the variation between these studies.

Additional information on the effect of cerebral perfusion on mild cognitive dysfunction in diabetic patients may be obtained from studies in patients with type 1 diabetes mellitus, as many of the underlying mechanisms may be common to both forms of diabetes. Indeed, cerebral hypoperfusion has been described in children and adults with type 1 diabetes mellitus [8-11], but not consistently [12], and its role in the development of cognitive decrements has not been established [11].

Two-dimensional phase-contrast (2D-PC) magnetic resonance angiography (MRA) is a non-invasive, accurate method for measuring total cerebral blood flow (total CBF) [13-15], and is therefore applicable for use in large groups of healthy participants. Relative total CBF, a measure of mean total cerebral perfusion, is obtained by dividing total CBF by brain volume [16].

Until now, the relation between cerebral perfusion, cognitive functioning and type 2 diabetes has not been investigated in the same study population. The aim of the current study was to investigate whether cerebral perfusion, as measured non-invasively with 2D-PC MRA volume flow quantification, differs between participants with and without type 2 diabetes and whether this could account for the decrease in cognitive functioning of patients with type 2 diabetes relative to controls.

\section{Methods}

Participants

We included participants of the Utrecht Diabetic Encephalopathy Study (UDES), a cross-sectional population-based study on determinants of impaired cognition in patients with type 2 diabetes. Data on cognition and brain imaging findings from this study have been reported previously [17]. Between September 2002 and November 2004, patients with type 2 diabetes were recruited through their general practitioner and control participants of at least 56 years were recruited from among the spouses or acquaintances of the patients. Therefore, patients were not selected for the presence or absence of diabetic complications or co-morbid conditions (e.g. hypertension). For inclusion, type 2 diabetic patients had to be 55 to 80 years of age, have a disease duration of at least 1 year, be functionally independent and speak Dutch. Exclusion criteria for all participants included a psychiatric or neurological disorder (unrelated to diabetes) that could influence cognitive functioning, history of alcohol or substance abuse, or history of dementia. For control participants, exclusion criteria additionally included fasting blood glucose $\geq 7.0 \mathrm{mmol} / \mathrm{l}$. Participants with a history of non-incapacitating stroke were included. Approval for the study was obtained from the medical ethics committee of the University Medical Center Utrecht, the Netherlands, and written, informed consent was provided by all participants.

For the present study, we excluded participants for whom MRI of the brain was not available due to MRI contraindications $(n=15)$ and missing $(n=8)$ or irretrievable $(n=10)$ digital MRI records. Hence, analyses were performed in 145 participants ( 98 patients with type 2 diabetes and 47 controls).

\section{Participant characteristics}

Information about the presence of vascular risk factors was assessed by means of a standardised interview and by physical and laboratory examinations. Blood pressure was measured at nine fixed time points during the day with an automatic blood pressure device (705CP; Omron, Hamburg, Germany). Hypertension was defined as a mean systolic blood pressure above $160 \mathrm{mmHg}$, a mean diastolic pressure above $95 \mathrm{mmHg}$ or the use of antihypertensive medication. Fasting glucose and $\mathrm{HbA}_{1 \mathrm{c}}$ levels were determined by means of a venous blood sample. The presence of macrovascular disease was defined as a history of myocardial infarction, stroke, vascular surgery or endovascular treatment for coronary, carotid or peripheral artery disease.

Magnetic resonance imaging

Brain MRI was performed on a $1.5 \mathrm{~T}$ scanner (Philips Medical Systems, Best, the Netherlands). The protocol consisted of axial T1 weighted (repetition time [TR] $234 \mathrm{~ms} /$ echo time [TE] $2 \mathrm{~ms}$ ), inversion recovery (IR; TR 2,900 ms/TE $22 \mathrm{~ms}$ ) and FLAIR (TR 6,000 ms/inversion time [TI] 2,000 ms/TE $100 \mathrm{~ms}$ ) scans, performed with $4 \mathrm{~mm}$ slice thickness, no slice gap and 38 slices, covering the entire brain, with a field of view of $230 \times 230 \mathrm{~mm}$ and a $256 \times 256$ scan matrix.

On the basis of two magnetic resonance (MR) localiser scans in the coronal and sagittal plane, a 2D-PC MR section was positioned at the level of the skull base to measure the volume flow in the internal carotid arteries (ICAs) and basilar artery (BA; TR $16 \mathrm{~ms}$; TE $9 \mathrm{~ms}$; flip angle $7.5^{\circ}$; field of view $250 \times 250 \mathrm{~mm}$; matrix $256 \times 256$; section thickness $5 \mathrm{~mm}$; averages 8 ; velocity sensitivity $100 \mathrm{~cm} / \mathrm{s}$; Fig. 1) [15]. 


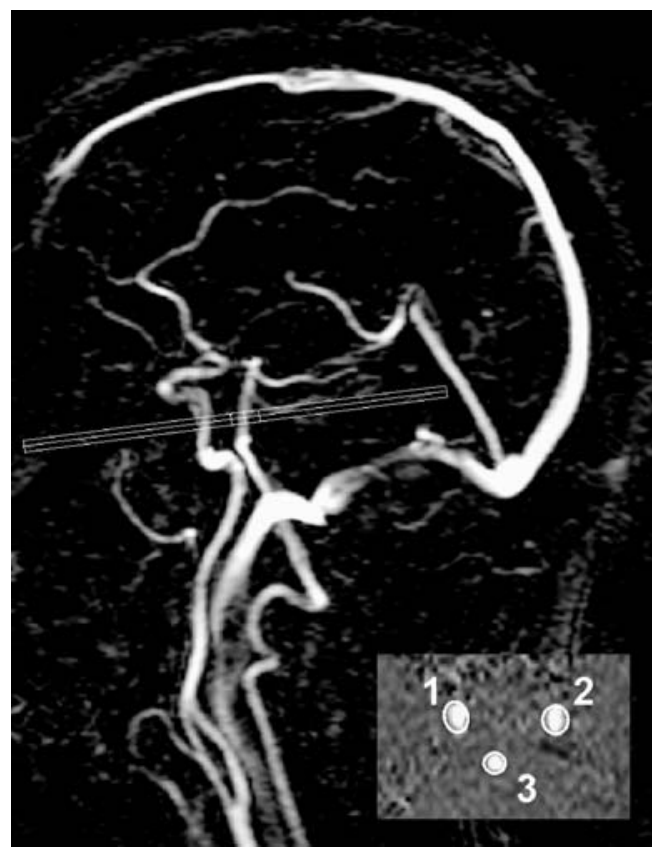

Fig. 1 Sagittal localiser magnetic resonance angiogram illustrating the positioning of a two-dimensional phase-contrast MR section to measure the volume flow through the internal carotid arteries and basilar artery. Quantitative magnetic resonance flow values were obtained by integrating across manually drawn regions that enclose the vessels. 1, right ICA; 2, left ICA; 3, basilar artery

\section{Data processing}

Assessment of brain volume Volumetric assessment of brain parenchyma volume was performed using an automated probabilistic segmentation method, which has been described previously [18]. In short, the algorithm is based on information from the T1-w, IR and FLAIR images. It uses the K-Nearest Neighbour classification technique that is based on both spatial information and voxel intensities. For each voxel the algorithm determines the probability that it is part of a specific brain tissue type. Segmentation and volumes of five different brain tissue types (grey matter, white matter, pericerebral cerebrospinal fluid, ventricles and white matter lesions) are calculated automatically.

Total brain volume was defined as the sum of the volumes of grey and white matter and white matter lesions.

Measurement of total cerebral blood flow and assessment of relative total brain perfusion Regions of interest were manually drawn closely around the vessel lumens of both ICAs and the BA on the phase-difference images (Fig. 1) and flow velocities were multiplied by the cross-sectional area of the pixels in the region of interest to obtain volume flow rates (in $\mathrm{ml} / \mathrm{s}$ ) [13-15]. The flow through the three vessels was then summed and multiplied by $60 \mathrm{~s} / \mathrm{min}$ to calculate the total CBF (in $\mathrm{ml} / \mathrm{min}$ ).
Because total $\mathrm{CBF}$ is influenced by brain size, we calculated mean total cerebral perfusion (total $\mathrm{CBF}$ relative to a participant's brain volume) by dividing total CBF (in $\mathrm{ml} / \mathrm{min}$ ) by brain volume (in $\mathrm{ml}$ ) and multiplying by 100 , thus obtaining a measure in $\mathrm{ml} / \mathrm{min}$ per $100 \mathrm{ml}$ brain tissue $[16,19]$.

Neuropsychological tests

All participants underwent an extensive neuropsychological evaluation, including 11 different tests addressing five cognitive domains: visuo-construction, attention and executive function, information processing speed, memory and abstract reasoning. Premorbid IQ was tested with the Dutch version of the National Adult Reading Test [20] and educational level was recorded in seven categories and transferred to years of education [21]. These tasks took about $90 \mathrm{~min}$ to complete. Summary scores for the five cognitive domains were constructed by converting the raw scores from the individual tests to standardised scores ( $z$ scores) that were based on the means and pooled standard deviations of the whole

Table 1 Characteristics of the participants

\begin{tabular}{|c|c|c|}
\hline & $\begin{array}{l}\text { With type } 2 \\
\text { diabetes }(n=98)\end{array}$ & $\begin{array}{l}\text { Without type } 2 \\
\text { diabetes }(n=47)\end{array}$ \\
\hline \multicolumn{3}{|l|}{ Demographic factors } \\
\hline Age (years) & $66.0(5.7)$ & $64.9(5.4)$ \\
\hline Sex $(\operatorname{men})^{\mathrm{a}}$ & $50(51)$ & $20(43)$ \\
\hline Level of education ${ }^{\mathrm{b}}$ & $4(3-5)$ & $4(3-5)$ \\
\hline Estimated premorbid IQ & $98.7(15.8)$ & $100.6(14.3)$ \\
\hline \multicolumn{3}{|l|}{ Vascular risk factors } \\
\hline BMI $\left(\mathrm{kg} / \mathrm{m}^{2}\right)$ & $28.2(4.3)$ & $27.3(5.1)$ \\
\hline Systolic blood pressure $(\mathrm{mmHg})$ & $147.3(19.9)$ & $138.7(19.2)$ \\
\hline Diastolic blood pressure $(\mathrm{mmHg})$ & $81.9(9.6)$ & $78.5(8.7)$ \\
\hline Hypertension $^{\mathrm{a}}$ & $79(81)$ & $16(34)$ \\
\hline History of stroke ${ }^{a}$ & $6(6)$ & $0(0)$ \\
\hline History of any vascular disease $\mathrm{a}^{\mathrm{a}}$ & $26(27)$ & $2(4)$ \\
\hline \multicolumn{3}{|l|}{ Diabetes-related factors } \\
\hline Fasting serum glucose $(\mathrm{mmol} / \mathrm{l})$ & $8.7(3.1)$ & $5.5(0.6)$ \\
\hline Total diabetes duration (years) & $8.6(6.1)$ & NA \\
\hline $\mathrm{HbA}_{1 \mathrm{c}}(\%)$ & $6.9(1.3)$ & $5.5(0.3)$ \\
\hline Insulin treatment $\mathrm{a}^{\mathrm{a}}$ & $28(29)$ & 0 \\
\hline \multicolumn{3}{|l|}{ Global cognitive performance } \\
\hline Composite $z$ score & $-0.07(0.06)$ & $0.14(0.06)$ \\
\hline \multicolumn{3}{|l|}{ Brain MRI measures } \\
\hline Lacunar infarcts ${ }^{\mathrm{a}}$ & $9(9)$ & $3(6)$ \\
\hline Large infarcts ${ }^{\mathrm{a}}$ & $6(6)$ & $1(2)$ \\
\hline White matter lesion volume (ml) & $2.8(1.2-5.0)$ & $1.9(0.9-3.6)$ \\
\hline Brain volume $(\mathrm{ml})$ & $1,076.2(103.1)$ & $1,106.7(87.5)$ \\
\hline
\end{tabular}

Data shown are means (SD or SE for $z$ score), medians (IQR) or a proportions (\%)

${ }^{\mathrm{b}}$ Seven categories, corresponding to years of education as follows: $<6$, $6-7,8,9,10-11,12-18$ and $>18$

NA, not applicable 
Table 2 Relation of type 2 diabetes and other (vascular) risk factors with relative total $\mathrm{CBF}$

Linear regression analysis, adjusted for age and sex ${ }^{*} p<0.05$

\begin{tabular}{|c|c|c|}
\hline & \multicolumn{2}{|c|}{ Relative total CBF (ml min $\left.{ }^{-1} 100 \mathrm{ml}^{-1}\right)$} \\
\hline & Regression coefficient $B$ & $95 \% \mathrm{CI}$ \\
\hline Diabetes (yes/no) & -2.3 & $-6.0,1.3$ \\
\hline Glucose $(\mathrm{mmol} / \mathrm{l})$ & -0.3 & $-0.9,0.4$ \\
\hline $\mathrm{HbA}_{1 \mathrm{c}}(\%)$ & -0.8 & $-2.2,0.6$ \\
\hline Hypertension (yes/no) & -5.0 & $-8.6,-1.4^{*}$ \\
\hline Diastolic BP (per $10 \mathrm{mmHg}$ elevation) & -2.1 & $-3.9,-0.3^{*}$ \\
\hline Systolic BP (per $10 \mathrm{mmHg}$ elevation) & -0.01 & $-0.9,0.9$ \\
\hline
\end{tabular}

population. Subsequently, $z$ scores of tasks belonging to the same cognitive domain were averaged. By averaging the $z$ scores of the five domains a composite $z$ score was calculated as a measure of global cognitive functioning.

Statistical analysis

Differences in neuropsychological performance and MR variables between type 2 diabetic patients and controls were analysed with multivariable linear regression adjusted for age, sex and estimated IQ.

Linear regression analyses with adjustment for age, sex and IQ were also performed to assess the relationship of diabetes and other vascular risk factors with relative total $\mathrm{CBF}$ and to investigate the association of relative total CBF with cognitive function.

\section{Results}

The baseline characteristics of the participants are outlined in Table 1. Patients with type 2 diabetes performed worse on neuropsychological tests and had smaller brain volumes than control participants without type 2 diabetes $(p<0.05$ for both, adjusted for age, sex and IQ; Table 1).

Mean relative total $\mathrm{CBF}$ in the entire study population was $51.9 \mathrm{ml} / \mathrm{min}$ per $100 \mathrm{ml}$ brain tissue, which, divided by brain tissue density $(1.034 \mathrm{~g} / \mathrm{ml})$ [19], corresponds to
$50.2 \mathrm{ml} / \mathrm{min}$ per $100 \mathrm{~g}$ brain tissue. Total CBF (uncorrected for brain volume) was lower in participants with than in those without type 2 diabetes (difference $-46.6 \mathrm{ml} / \mathrm{min}$; 95\% CI -88.6, -4.6). However, relative total CBF (total CBF per $100 \mathrm{ml}$ brain parenchyma volume) was not significantly different in patients with type 2 diabetes compared with those without (difference $-2.3 \mathrm{ml} \mathrm{min}{ }^{-1}$ $100 \mathrm{ml}^{-1}$; 95\% CI -6.0, 1.3; Table 2).

Hypertension (CBF -5.0 ml min ${ }^{-1} 100 \mathrm{ml}^{-1} ; 95 \% \mathrm{CI}-8.6$, $-1.4)$ and diastolic blood pressure $\left(\mathrm{CBF}-2.1 \mathrm{ml} \mathrm{min}^{-1}\right.$ $100 \mathrm{ml}^{-1} ; 95 \% \mathrm{CI}-3.9,-0.3$ per $10 \mathrm{mmHg}$ elevation) were significantly associated with relative total CBF (Table 2). We found no interaction between hypertension or blood pressure and type 2 diabetes. No other diabetes-related factors or vascular risk factors were associated with relative total CBF (Table 2).

Across the whole population, relative total $\mathrm{CBF}$ was positively associated with information processing speed, attention and executive function, visuoconstruction and global cognitive performance (Table 3), with a 0.09 SD increase in composite $z$ score per $10 \mathrm{ml} \mathrm{min}{ }^{-1} 100 \mathrm{ml}^{-1}$ increase in relative total CBF; 95\% CI 0.03, 0.15. Adjustment for hypertension, white matter lesions and large infarcts on MRI did not change this association. Moreover, exclusion of patients with large infarcts on MRI $(n=6)$ did not affect the results (data not shown). There was also a positive relationship between relative total $\mathrm{CBF}$ and cognitive functioning within the diabetic group alone (Table 3).

Table 3 Relation between relative total CBF $\left(10 \mathrm{ml} \mathrm{min}^{-1} 100 \mathrm{ml}^{-1}\right)$ and cognitive function

\begin{tabular}{|c|c|c|c|c|c|c|}
\hline & $\begin{array}{l}\text { Information } \\
\text { processing speed }^{\text {a }}\end{array}$ & $\begin{array}{l}\text { Attention and } \\
\text { executive function }^{\mathrm{a}}\end{array}$ & Memory $^{a}$ & $\begin{array}{l}\text { Abstract } \\
\text { reasoning }^{\mathrm{a}}\end{array}$ & $\begin{array}{l}\text { Visuo- } \\
\text { construction }^{\mathrm{a}}\end{array}$ & $\begin{array}{l}\text { Global cognitive } \\
\text { performance }^{\mathrm{a}}\end{array}$ \\
\hline \multicolumn{7}{|c|}{ Relative total $\mathrm{CBF}^{\mathrm{b}}$} \\
\hline All participants & $0.14 *(0.02,0.26)$ & $0.11 * *(0.03,0.19)$ & $-0.02(-0.09,0.05)$ & $0.08(-0.05,0.21)$ & $0.16^{*}(0.02,0.30)$ & $0.09^{* *}(0.03,0.15)$ \\
\hline $\begin{array}{l}\text { Type } 2 \text { diabetic } \\
\text { patients }\end{array}$ & $0.16(-0.01,0.32)$ & $0.13 *(0.01,0.24)$ & $-0.03(-0.13,0.06)$ & $0.18(-0.01,0.37)$ & $0.21 *(0.02,0.40)$ & $0.12 * *(0.03,0.21)$ \\
\hline
\end{tabular}

Linear regression analysis with regression coefficients B $(95 \% \mathrm{CI})$, adjusted for age, sex and IQ

${ }^{\mathrm{a}} z$ score

b $10 \mathrm{ml} \mathrm{min}^{-1} 100 \mathrm{ml}^{-1}$

${ }^{*} p<0.05, * * p<0.01$ 


\section{Discussion}

We were interested in determining the relation between type 2 diabetes and cerebral perfusion to identify underlying vascular mechanisms and to clarify the pathogenesis of impaired cognitive functioning and increased risk of dementia in type 2 diabetes. We have shown that relative total CBF, expressed in $\mathrm{ml} / \mathrm{min}$ per $100 \mathrm{ml}$ brain tissue, was positively related to cognitive functioning, but that this relation was independent of type 2 diabetes. Differences in cognitive functioning between participants with and without type 2 diabetes could therefore not be attributed to differences in total cerebral perfusion. Total CBF, cerebral perfusion and brain volume can all change as a consequence of type 2 diabetes, but apparently these changes can occur independently.

Thus far, the few studies on cerebral perfusion in type 2 diabetes measured regional CBF with SPECT or PET and included only a small number of patients (27 and 16 patients, respectively) or were performed in patients with severe diabetic complications (e.g. symptomatic cerebral microangiopathy) $[5,6]$. A lower regional $\mathrm{CBF}$ in all regions of the cortex $[5,6]$ and a lower overall $\mathrm{CBF}[6]$ in the diabetic group than in the non-diabetic group have been reported. Based on these findings, we hypothesised that total cerebral hypoperfusion might explain cognitive dysfunction in our patients with type 2 diabetes. However, the methodological issues mentioned above may explain the lack of consistency with previous findings.

Differences in total CBF between individuals can, among others, be attributed to differences in brain size $[16,19]$. Quantitative flow measurements in the ICAs and BA by 2D-PC MRA, expressed per $100 \mathrm{ml}$ brain volume, provide mean total cerebral perfusion values that are comparable to normal values of cerebral perfusion measured by other imaging techniques $\left(50.0 \mathrm{ml} \mathrm{min}^{-1} 100 \mathrm{~g}^{-1}\right)$ [22]. Patients with type 2 diabetes are prone to a modest degree of brain atrophy [23]. This explains the difference in total CBF between patients with and without type 2 diabetes and the lack of a significant difference in mean total cerebral perfusion (relative total CBF). In a study of patients with symptomatic arterial disease, diabetes was also associated with a lower total CBF $(\beta-42.0 \mathrm{ml} / \mathrm{min}$, comparable with our results), but correction for brain volume was not performed [24]. The authors stated that adjustment for age could have accounted for the effect of brain atrophy, but this remains an assumption. Sabri et al. [6] also observed that the effect of type 2 diabetes on regional CBF might be confounded by concomitant brain atrophy, which was measured with a relatively crude visual ordinal rating scale.

No previous studies have demonstrated a relation between reduced relative total $\mathrm{CBF}$ and mild cognitive impairment using 2D-PC MRA flow measurements through the ICAs and BA. Only one previous study found a lower total CBF in patients with dementia, but the investigators did not correct for brain volume, although patients with dementia had significantly more brain atrophy [25].

We show that impaired cognitive functioning in patients with type 2 diabetes relative to controls is not attributable to the relative total $\mathrm{CBF}$ under resting conditions. Nevertheless, it is possible that cerebrovascular reactivity, the vasodilatory response to a vascular challenge, is impaired in patients with type 2 diabetes. Conceivably, such an impaired vascular reactivity could have an effect on the relation between type 2 diabetes and cognitive dysfunction.

From our findings we cannot exclude that more focal areas with hypoperfusion were present in our population of patients with type 2 diabetes, as has been observed previously, especially in patients with type 1 diabetes mellitus [8-11]. However, these focal changes in hypoperfusion do not seem to affect the overall perfusion of the brain. A difference between these previous studies and ours is that we corrected for brain volume in the present study based on MR segmentation of the brain parenchyma. Without correction for brain volume, cerebral perfusion may be underestimated in patients with diabetes mellitus relative to controls, due to increased atrophy in the former compared with controls.

In this cross-sectional study we combined data on cerebral perfusion, type 2 diabetes and cognitive function. We showed that reduced total cerebral perfusion was associated with impaired cognitive functioning. It is as yet unclear whether cerebral hypoperfusion is the cause (i.e. through moderate ischaemia) or the consequence (i.e. through reduced demand) of impaired cognition. In any case, the effect of type 2 diabetes mellitus on cognitive performance in our population could not be explained by a reduced total cerebral perfusion.

Acknowledgement This research was supported financially by the Dutch Diabetes Research Foundation (grant nos 2001.00.023 and 2003.01.004)

Duality of interest The authors declare that there is no duality of interest associated with this manuscript.

Open Access This article is distributed under the terms of the Creative Commons Attribution Noncommercial License which permits any noncommercial use, distribution, and reproduction in any medium, provided the original author(s) and source are credited.

\section{References}

1. Stewart R, Liolitsa D (1999) Type 2 diabetes mellitus, cognitive impairment and dementia. Diabet Med 16:93-112

2. Ishiwata A, Sakayori O, Minoshima S, Mizumura S, Kitamura S, Katayama Y (2006) Preclinical evidence of Alzheimer changes in progressive mild cognitive impairment: a qualitative and quantitative SPECT study. Acta Neurol Scand 114:91-96 
3. Jagust WJ, Eberling JL, Reed BR, Mathis CA, Budinger TF (1997) Clinical studies of cerebral blood flow in Alzheimer's disease. Ann NY Acad Sci 826:254-262

4. Johnson KA, Moran EK, Becker JA, Blacker D, Fischman AJ, Albert MS (2007) Single photon emission computed tomography perfusion differences in mild cognitive impairment. J Neurol Neurosurg Psychiatry 78:240-247

5. Nagamachi S, Nishikawa T, Ono S et al (1994) Regional cerebral blood flow in diabetic patients: evaluation by $N$-isopropyl- ${ }^{123}$ I-IMP with SPECT. Nucl Med Commun 15:455-460

6. Sabri O, Hellwig D, Schreckenberger M et al (2000) Influence of diabetes mellitus on regional cerebral glucose metabolism and regional cerebral blood flow. Nucl Med Commun 21:19-29

7. van Laar PJ, van der GY, Mali WP, van der Grond J, Hendrikse J (2008) Effect of cerebrovascular risk factors on regional cerebral blood flow. Radiology 246:198-204

8. Keymeulen B, Jacobs A, de Metz K, de Sadeleer C, Bossuyt A, Somers G (1995) Regional cerebral hypoperfusion in long-term type 1 (insulin-dependent) diabetic patients: relation to hypoglycaemic events. Nucl Med Commun 16:10-16

9. Quirce R, Carril JM, Jimenez-Bonilla JF et al (1997) Semiquantitative assessment of cerebral blood flow with ${ }^{99 \mathrm{~m}} \mathrm{Tc}-$ HMPAO SPET in type I diabetic patients with no clinical history of cerebrovascular disease. Eur J Nucl Med 24:1507-1513

10. Rodriguez G, Nobili F, Celestino MA et al (1993) Regional cerebral blood flow and cerebrovascular reactivity in IDDM. Diabetes Care 16:462-468

11. Salem MA, Matta LF, Tantawy AA, Hussein M, Gad GI (2002) Single photon emission tomography (SPECT) study of regional cerebral blood flow in normoalbuminuric children and adolescents with type 1 diabetes. Pediatr Diabetes 3:155-162

12. Grill V, Gutniak M, Bjorkman O et al (1990) Cerebral blood flow and substrate utilization in insulin-treated diabetic subjects. Am J Physiol 258:E813-E820

13. Bakker CJ, Kouwenhoven M, Hartkamp MJ, Hoogeveen RM, Mali WP (1995) Accuracy and precision of time-averaged flow as measured by nontriggered 2D phase-contrast MR angiography, a phantom evaluation. Magn Reson Imaging 13:959-965
14. Bakker CJ, Hartkamp MJ, Mali WP (1996) Measuring blood flow by nontriggered 2D phase-contrast MR angiography. Magn Reson Imaging 14:609-614

15. Spilt A, Box FM, van der Geest RJ et al (2002) Reproducibility of total cerebral blood flow measurements using phase contrast magnetic resonance imaging. J Magn Reson Imaging 16:1-5

16. Vernooij MW, van der Lugt A, Ikram MA et al (2008) Total cerebral blood flow and total brain perfusion in the general population: The Rotterdam Scan Study. J Cereb Blood Flow Metab 28:412-419

17. Manschot SM, Brands AM, van der Grond J et al (2006) Brain magnetic resonance imaging correlates of impaired cognition in patients with type 2 diabetes. Diabetes 55:1106-1113

18. Anbeek P, Vincken KL, van Bochove GS, van Osch MJ, van der Grond J (2005) Probabilistic segmentation of brain tissue in MR imaging. Neuroimage 27:795-804

19. Strandgaard S (1991) Cerebral blood flow in the elderly: impact of hypertension and antihypertensive treatment. Cardiovasc Drugs Ther 4(Suppl 6):1217-1221

20. Bright P, Jaldow E, Kopelman MD (2002) The National Adult Reading Test as a measure of premorbid intelligence: a comparison with estimates derived from demographic variables. J Int Neuropsychol Soc 8:847-854

21. Hochstenbach J, Mulder $\mathrm{T}$, van Limbeek J, Donders R, Schoonderwaldt H (1998) Cognitive decline following stroke: a comprehensive study of cognitive decline following stroke. J Clin Exp Neuropsychol 20:503-517

22. Kirkness CJ (2005) Cerebral blood flow monitoring in clinical practice. AACN. Clin Issues 16:476-487

23. van Harten B, de Leeuw FE, Weinstein HC, Scheltens P, Biessels GJ (2006) Brain imaging in patients with diabetes: a systematic review. Diabetes Care 29:2539-2548

24. van Raamt AF, Appelman AP, Mali WP, van der Graaf Y (2006) Arterial blood flow to the brain in patients with vascular disease: the SMART Study. Radiology 240:515-521

25. Spilt A, Weverling-Rijnsburger AW, Middelkoop HA et al (2005) Late-onset dementia: structural brain damage and total cerebral blood flow. Radiology 236:990-995 